\title{
Assessment of obstetric and gynaecological problems in females with bleeding disorders
}

\author{
Shruti Ashok Panchbudhe, Ashwini Sudhir Desai*
}

Department of Obstetrics and Gynaecology, Seth G.S. Medical College, Mumbai, Maharashtra, India

Received: 11 February 2021

Accepted: 10 March 2021

\section{*Correspondence:}

Dr. Ashwini Sudhir Desai,

E-mail: asdesai111@gmail.com

Copyright: $@$ the author(s), publisher and licensee Medip Academy. This is an open-access article distributed under the terms of the Creative Commons Attribution Non-Commercial License, which permits unrestricted non-commercial use, distribution, and reproduction in any medium, provided the original work is properly cited.

\begin{abstract}
Background: Inherited bleeding disorders are not common but they are lifelong. Their effects on women are far greater than previously realised. Many clinicians are not familiar with these disorders but may encounter such women under acute conditions. Objectives were to study various obstetric and gynaecological problems in females with bleeding disorders and to assess the type of management given for these disorders.

Methods: This was a prospective observational study carried out at Department of Obstetrics and Gynaecology at a tertiary care hospital in which 30 women of known bleeding disorder were studied and various obstetric and gynaecological problems including menorrhagia, metrorrhagia, dysmenorrhoea, mid-cycle pain, conception, haemorrhagic ovarian cyst, etc. were identified and studied in them.

Results: 30 patients of known bleeding disorder who were found to have obstetric and gynaecological problem were studied. Idiopathic thrombocytopenic purpura constituted the major bleeding disorder (23\%), followed by von Willebrand's disease (17\%) in our study. 21 patients had gynaecological problem and the most common gynaecological problem was menorrhagia (62\%), followed by hemoperitoneum (10\%), mid cycle pain (10\%), persistent haemorrhagic cyst (7\%), dysmenorrhea (7\%) and endometriosis (4\%). 20 patients had obstetric problems of which postpartum haemorrhage (59\%) was a major problem followed by recurrent pregnancy loss (33\%) and infertility $(8 \%)$. The study concluded that both obstetric and gynaecological problems are common in patients of bleeding disorders and occur in distribution $66.66 \%$ and $70 \%$ respectively.

Conclusions: The study conducted shows that obstetric and gynaecological problems are very common in patients of bleeding disorders and thus optimal management of these problems requires a multidisciplinary team of approach.
\end{abstract}

Keywords: Antiphospholipid antibody syndrome, Idiopathic thrombocytopenic purpura, Recurrent pregnancy loss, Von-Willebrand's disease

\section{INTRODUCTION}

Bleeding disorders can affect both men and women. They can be inherited or acquired during a person's life. Mild inherited bleeding disorders are common, while severe inherited bleeding disorders are rare, affecting as few as one in 5,000 to one in $1,000,000$ people. ${ }^{1}$ Certain types of medications, malignancies, and autoimmune disorders can cause acquired bleeding disorders. Because the most common bleeding disorders, including Von Willebrand's disease (VWD), manifest primarily by mucosal bleeding, females are often more likely to be symptomatic due to excessive bleeding with menstruation (menorrhagia), ovulation, and childbirth (peripartum hemorrhage). Von Willebrand's disease is the most frequent inherited bleeding disorder, followed by mild coagulation factor deficiencies such as factor XI deficiency and mild platelet disorders. Evidence has shown that not only there is an increase prevalence of menorrhagia associated with bleeding disorders, but also that this complication significantly disrupts the quality of life of these women., ${ }^{2,3}$ Between $40 \%$ and $50 \%$ of women experiencing menorrhagia, report that they are limited in their activities and that they find working more difficult during their menstrual periods. ${ }^{4}$ 
Bleeding disorders have a significant impact on women's health and quality of life. ${ }^{5,6}$ Women with bleeding disorders have reduced quality of life that negatively affects their academic, professional, and social life. Longlasting menorrhagia leads to iron deficiency anemia, with all its consequences on physical and mental wellbeing. Many women are not aware that their symptoms are abnormal and do not seek medical advice. Even when they do seek help, diagnosis of bleeding disorders is often overlooked and appropriate treatment is not provided due to lack of awareness among health professional. Since menorrhagia in women with bleeding disorders frequently begins at menarche, these factors could have an impact on the social and academic development of the adolescent female. Women with bleeding disorders are therefore more likely to have unnecessary surgical intervention, including hysterectomy, at an early age. Heavy and prolonged menstrual bleeding and pain may lead to marital disharmony and also fertility problems. This in turn, further compromises a women's mental and psychological wellbeing.

\section{Aims and objectives}

To study various obstetric and gynaecological problems in females with bleeding disorders. To assess the type of management given for these disorders.

\section{METHODS}

This study was conducted in the Department of Obstetrics and gynecology at our tertiary care hospital. 30 patients were included in the study for a period of 2 years. All the eligible subjects were recruited into the study consecutively by convenient sampling till the sample size was reached.

\section{Inclusion criteria}

All females with diagnosed bleeding disorders presenting with obstetric and gynaecological problems were studied after taking consent. The various disorders included: 1) Inherited bleeding disorders: i) Von Willebrand's disease, ii) haemophilia, iii) protein $\mathrm{C}$ and $\mathrm{S}$ deficiency etc. 2) acquired bleeding disorders: idiopathic thrombocytopenic purpura, systemic lupus erythematosus, liver disease, aplastic anaemia.

\section{Exclusion criteria}

Women with an acute onset bleeding disorder due to an obstetric complication like disseminated intravascular coagulation due to PIH, abruptio placentae etc. Women with obstetric and gynaecological problem due to some pathology in the reproductive system.

\section{Study procedure}

A careful history serves both, to establish the degree of clinical suspicion for a bleeding disorder and to provide clues to a specific diagnosis. In this study history taking included the haematological disease the female had been suffering, the various gynaecological and obstetric problems in these females and the treatment options for these problems. Presence of hemorrhagic symptoms were noted long with a detailed menstrual history. A family history of any bleeding disorder was also obtained. A detailed obstetrical history with regards to parity, mode of delivery, pregnancy related complications like antepartum, intrapartum postpartum haemorrhage, need of blood and blood related products noted.

Laboratory investigation were also noted which included the following- haemoglobin, platelet count, complete blood count, liver function tests, renal function tests, skin bleeding time and clotting time. Various screening and specific tests which were conducted in the department of hematology were also noted during the study. Screening coagulation tests like prothrombin time (PT), activated prothrombin time (APTT), thrombin time (TT) and specific tests like Von Willebrand's factor assay, factor 8 assay, platelet function studies, flow cytometry for specific monoclonal antibodies etc. Also in patients presenting with recurrent pregnancy loss lupus anticoagulant and anti cardiolipin antibodies were done to arrive at a diagnosis of APLA syndrome. Thus various obstetric and gynaecological problems were found in patients of bleeding disorders which were studied and treated according to the various treatment options available.

\section{RESULTS}

A total 30 patients of known bleeding disorders were studied. Out of 30 patients in the study, 25 were married and 5 patients were unmarried. Following number of patients were referred from haematology for obstetrical and gynaecological problems:

Table 1: Frequency of bleeding disorder in the study population.

\begin{tabular}{|lll|}
\hline $\begin{array}{l}\text { Disorder } \\
\text { Idiopathic thrombocytopenic } \\
\text { purpura }\end{array}$ & 7 & 23 \\
\hline Von-Willebrand's disease & 5 & 16.66 \\
\hline Protein C and S deficiency & 3 & 10 \\
\hline Platelets aggregation defect & 2 & 6.66 \\
\hline APLA syndrome & 2 & 6.66 \\
\hline ITP with APLA syndrome & 2 & 6.66 \\
\hline Glanzmann's thrombasthenia & 2 & 6.66 \\
\hline SLE induced thrombocytopenia & 2 & 6.66 \\
\hline SLE with acquired vWD & 1 & 3.33 \\
\hline $\begin{array}{l}\text { vWD with protein C and S } \\
\text { deficiency }\end{array}$ & 1 & 3.33 \\
\hline Factor XI deficiency & 1 & 3.33 \\
\hline $\begin{array}{l}\text { SLE with ITP with APLA } \\
\text { syndrome }\end{array}$ & 1 & 3.33 \\
\hline HIV induced thrombocytopenia 1 & 3.33 \\
\hline
\end{tabular}


The thirty patients presented had known bleeding disorder and were further managed with regards to their obstetric and gynaecological complaints. These patients had varied types of bleeding disorder. Total thirteen different types of bleeding disorder were presented. The maximum number of patients were of idiopathic thrombocytopenic purpura followed by von Willebrand's disease accounting for $23 \%$ and $16 \%$ respectively.

\section{Gynaecological problems}

Out of 30 patients 21 patients had gynaecological problems. Out of these 21 patients, 5 patients presented with multiple gynaecological problems. The most common gynaecological problem was menorrhagia seen in $85 \%$. The rest of the patients presented with hemoperitonium (3), mid cycle pain (3), persistent haemorrhagic cyst (2), dysmenorrhea (2) and endometriosis (1). Some of these problems coexisted in the same patients. Multiple gynaecological problems were seen in three patients of Von-Willebrand's disease, one patient of Glanzmann's thrombasthenia and one patient ITP.

The following problems in these patients were persistent haemorrhagic cyst, mid cycle, menorrhagia in $1 \mathrm{vWD}$, menorrhagia and hemoperitonium in 2 vWD, dysmenorrhea, menorrhagia and mid-cycle pain in Glanzmann's thromboasthenia and menorrhagia, endometriosis and dysmenorrhea in ITP with APLA syndrome. The presentation of gynaecological problem was different in different bleeding disorder. Out of 7 patients of idiopathic thrombocytopenic purpura 4 had gynaecological problems all of which presented with only menorrhagia. However, in case of Von Willebrand's disease all 5 patients had gynaecological complaint and also they presented with multiple problems as mentioned above.

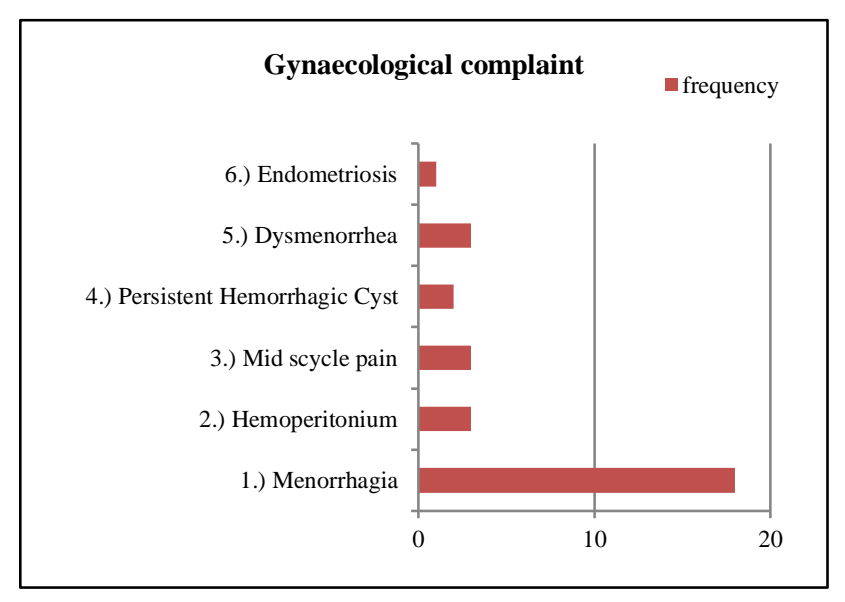

Figure 1: Gynaecological complaint.

\section{Management of gynaecological problems}

The management of gynaecological problems was mainly medical. The medical line of management included hormonal treatment, antifibrinolytics agents (tranexamic acid and ethamsylate) and NSAIDs like mefenamic acid. All the 21 patients required some form of medical treatment while 13 patients required blood and blood products in the form of platelets and cryoprecipitates. Some cases required conservative surgical management in the form of endometrial ablation (2) and dilatation and curettage (1) for menorrhagia. Surgical management was usually avoided in these patients due to the risk of bleeding during and after surgery however one case of HIV induced thrombocytopenia who presented with hemoperitonium required definitive surgical procedure in the form of exploratory laparotomy for hemoperitonium.

\section{Obstetric problems in females with bleeding disorders}

Obstetrical problems were seen in 20 patients. Recurrent pregnancy loss was in 7 patients and PPH occurred in 9 patients. 2 patients had combined obstetric problem which was RPL and PPH. 5 patients also had past history of PPH. Thus the total number of obstetric problems were PPH (16) and RPL (9). History of infertility was seen in two patients of which one had primary and one had secondary infertility.

Table 2: Frequency of obstetric problems.

\begin{tabular}{|lll|}
\hline Obstetrical problem & $\begin{array}{l}\text { Total number } \\
\text { of problems }\end{array}$ & Percentage \\
\hline $\begin{array}{l}\text { Recurrent pregnancy } \\
\text { loss }\end{array}$ & 9 & 59 \\
\hline $\begin{array}{l}\text { Post-partum } \\
\text { haemorrhage }\end{array}$ & 16 & 33 \\
\hline Infertility & 2 & 8 \\
\hline
\end{tabular}

Patients with haematological disorder of factor XI deficiency, APLA syndrome and protein $\mathrm{C}$ and $\mathrm{S}$ deficiency had obstetric complication in the form of recurrent pregnancy loss while two of them also had history of postpartum haemorrhage. All patients with ITP who had obstetric complication had history of postpartum haemorrhage. Obstetric complications were noted in $66 \%$ of patients with SLE and $40 \%$ patients of VonWillebrand's disease respectively.

\section{Obstetric course, outcome and management}

Pregnant patients of bleeding disorder were followed up till the end of their pregnancy. In 9 patients the pregnancy outcome was full term normal delivery except in 4 cases each of ITP with APLA, APLA syndrome, SLE induced thrombocytopenia and factor XI deficiency who had preterm vaginal delivery. One patient of Protein $\mathrm{C}$ and $\mathrm{S}$ deficiency who had history of recurrent pregnancy loss and past history of PPH presented with incomplete abortion and she required curettage.

All the patients of PPH who presented in the present pregnancy were managed with oxytocin drip and prostaglandin analogue. Some patients required blood 
and blood products during the course of their management. Out of 9 patients of RPL 6 were pregnant out of which only 2 patients had FTND, 1 patient had incomplete abortion and 3 patients had preterm vaginal delivery.

Table 3: Various obstetric problems in individual patients of bleeding disorders.

\begin{tabular}{|c|c|c|c|c|c|c|}
\hline Haematological disorder & $\begin{array}{l}\text { No. of } \\
\text { patients }\end{array}$ & $\begin{array}{l}\text { No. of patients with } \\
\text { obstetrical problem }\end{array}$ & $\begin{array}{l}\text { Recurrent } \\
\text { pregnancy loss }\end{array}$ & $\begin{array}{l}\text { Post-partum } \\
\text { haemorrhage }\end{array}$ & Infertility & Percentage \\
\hline $\begin{array}{l}\text { Idiopathic } \\
\text { thrombocytopenic } \\
\text { purpura }\end{array}$ & t the & 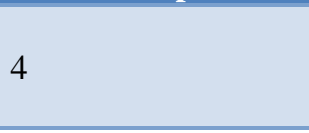 & - & - & - & 57.1 \\
\hline $\begin{array}{l}\text { Von-Willebrand's } \\
\text { disease }\end{array}$ & 5 & 2 & - & 1 & 1 & 40 \\
\hline $\begin{array}{l}\text { Protein } \mathrm{C} \text { and } \mathrm{S} \\
\text { deficiency }\end{array}$ & 3 & 3 & 3 & 1 & - & 100 \\
\hline $\begin{array}{l}\text { Platelet's aggregation } \\
\text { defect }\end{array}$ & 2 & 1 & - & 1 & - & 50 \\
\hline APLA syndrome & 2 & 2 & 2 & - & - & 100 \\
\hline $\begin{array}{l}\text { Glanzmann's } \\
\text { thrombasthenia }\end{array}$ & 2 & 1 & - & - & 1 & 50 \\
\hline $\begin{array}{l}\text { SLE induced } \\
\text { thrombocytopenia }\end{array}$ & 3 & 2 & - & 2 & - & 66.6 \\
\hline Factor XI deficiency & 1 & 1 & 1 & 1 & - & 100 \\
\hline
\end{tabular}

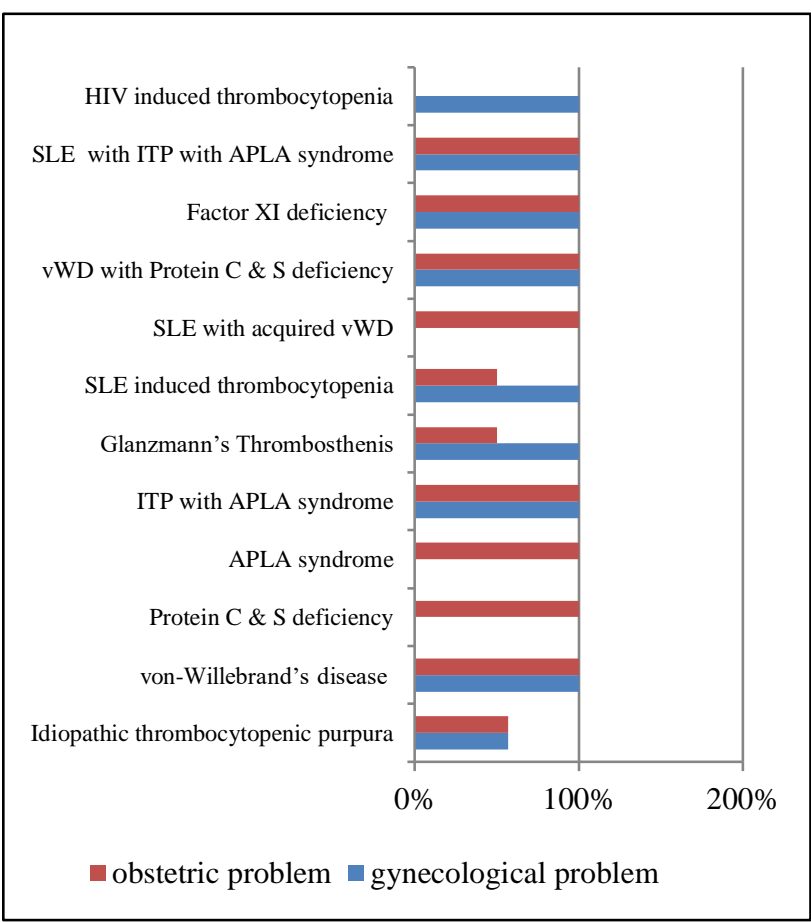

Figure 2: Combined obstetric and gynaecological problems in patients of bleeding disorders.

When considered the combined problems in the patients of bleeding disorder we found that both obstetrical and gynaecological problems were equally significant in these patients. Total 21 patients presented with gynaecological problems and 20 patients presented with obstetrical problems out of the 30 patients. So, the prevalence of gynaecological problem was $70 \%$ whereas prevalence of obstetrical problem was $66.66 \%$. However, with the exception of HIV induced thrombocytopenia all the disorders presented with obstetrical problems whereas gynaecological problem was absolutely absent in three disorders namely Protein $\mathrm{C}$ and $\mathrm{S}$ deficiency, APLA syndrome and SLE acquired vWD.

\section{DISCUSSION}

Gynaecological and obstetric problems were studied in 30 patients of known congenital and acquired bleeding disorder. Apart from the other symptoms of bleeding disorders, gynaecological and obstetric manifestation form the main stem of the symptoms in women's life. The current study evaluates a complete symptomatology and presentation of both gynaecological and obstetric problems the women had been suffering right from the beginning of her reproductive age till date.

Out of the total 30 patients presented, almost all had one or the other obstetric or gynaecological problem. $70 \%$ patients had gynaecological complaints whereas $66.66 \%$ patients had obstetric problems. With regards to the individual bleeding disorder the largest subgroup of patients were found with ITP (23\%) followed by vWD (17\%). Few patients of some rare bleeding disorder like SLE with acquired VWD, vWD with protein $\mathrm{C}$ and $\mathrm{S}$ deficiency, factor XI deficiency and HIV induced thrombocytopenia compromised the remainder. Though some of the bleeding disorders had relatively uncommon general symptoms but they presented a significant 
bleeding problem either during menses or during delivery.

Menstruation is a crucial haemostatic challenge that can be associated with excessive bleeding in the presence of any haemostatic defect during the reproductive age group. Therefore, menorrhagia can be the presenting symptom of a bleeding disorder (especially in its mild form) in otherwise asymptomatic women. It is defined as bleeding that lasts for more than seven days or results in the loss of more than $80 \mathrm{ml}$ of blood per menstrual cycle. ${ }^{7}$ Women with bleeding disorders commonly present with adolescent menorrhagia at menarche which is the first haemostatic challenge for these young girls. Of the total gynaecological problems presented, menorrhagia formed the major disturbing complaint which was present in $62 \%$ cases. The assessment of menorrhagia was done on the basis of patients subjective perception of menstruation which included number of days of bleeding, cycle length, number of pads soaked per day etc. In a study conducted by Siboni et al $59 \%$ of women had menorrhagia and in this study $62 \%$ of women had menorrhagia. ${ }^{8}$ Most of the patients of menorrhagia responded to the conservative medical management which included hormonal treatment, antifibrinolytics, and NSAIDS. Two patients required conservative surgical procedure in the form of endometrial ablation and one patient required dilatation and curettage. Most of the patients also required blood and blood products during their management like platelet transfusion if menorrhagia was associated with idiopathic or acquired thrombocytopenia and cryoprecipitate if menorrhagia was associated with Von Willebrand's disease.

Apart from menorrhagia as the significant gynaecological problem, the other gynaecological problems were also taken into consideration. These included hemoperitonium in 3 patients ( 2 of $\mathrm{VWD}$ and 1 of HIV induced thrombocytopenia) i.e. $10 \%$, mid cycle pain in 3 patients ( 2 of vWD and 1 of Glanzmann's thrombocytopenia) i.e. $10 \%$, persistent haemorrhagic cyst in 2 patients of vWD i.e. $7 \%$, dysmenorrhea in 2 patients (1 of ITP with APLA and 1of Glanzmann's thrombocytopenia) i.e. 7\% and endometriotic cyst in 1 patient of ITP with APLA i.e. $4 \%$. Hemoperitonium which was found in 3 patients was managed conservatively by medical line of treatment including antifrinolytics, blood, platelets and factor concentrate except in one patient of HIV induced thrombocytopenia who was managed with definitive surgical approach i.e. exploratory laparotomy in view of ultrasonography findings suggestive of rupture of ovarian cyst and required blood and platelet transfusion prior, during and after surgery. The conservative management with blood products and factor concentrate was successful in avoiding surgery in two of the three patients of bleeding disorders. Similarly, a study conducted by Payne reported that conservative management can avoid surgery in these patients and recurrent episodes may be prevented by suppression of ovulation. ${ }^{9}$
Endometriosis was found in one patient of ITP with APLA syndrome. Several studies have demonstrated increased rates of endometriosis in female with heavier menses presumably due to the increased rate of retrograde menstruation, a probable aetiology of endometriosis. Midcycle pain was found in 3 patients, two of vWD and one of Glanzmann's thromboasthenia. A female with a bleeding disorder may bleed excessively at the time of ovulation and experience a great deal of pelvic pain which is greatly magnified in these females.

Similarly, dysmenorrhea was seen in 2 patients, one of ITP with APLA syndrome and other with Glanzmann's thromboasthenia, both these patients were treated conservatively with NSAIDS. In females with bleeding disorder has coexistent endometriosis, the tissue found outside the uterus may bleed excessively, causing peritoneal irritation and pain.

Persistent haemorrhagic cyst was found in 2 patients of vWD which accounts for $7 \%$ of the total gynaecological problems found. Both these patients were treated conservatively with hormonal treatment and clotting factor replacement. Recurrence of haemorrhagic cyst was itself a manifestation of bleeding disorder. In one patient of vWD it was found that there is recurrence of haemorrhagic cyst after stopping combined oral contraceptive pills and therefore this patient was continuously on COC pills to inhibit ovulation and thus to prevent recurrences of haemorrhagic ovarian cyst.

From the above data collected it was found that a varied number of gynaecological problems were found in bleeding disorder patient. It was also noted that all patients who were detected to have bleeding disorder disclosed their bleeding problems only in response to leading questions, therefore this study insisted that history should be taken meticulously in each and every patient of bleeding disorder. It was also found that although a menorrhagia was a predominant problem, it was a subjective issue, as in families of type I vWD who have dominantly inherited the history of menorrhagia from their maternal grandmother and mother, daughters might consider their excessive menstrual blood loss as normal.

The total number of obstetric problems found were comparable to gynaecological problems. Obstetric problems were postpartum haemorrhage, recurrent pregnancy loss and infertility which were found in 59\%, $33 \%$ and $8 \%$ respectively.

Pregnancy is accompanied by increased concentrations of fibrinogen, FVII, FVIII, FX and Von Willebrand's factor (VWF). ${ }^{10}$ Factor VIII and VWF levels rise even in haemophilia carriers or women with VWD. Factor II, FV and FIX are relatively unchanged. Plasminogen activator inhibitor type 1 (PAI-1) levels are increased. All of these changes contribute to the hypercoagulable state of pregnancy, and, in women with bleeding disorders, 
contribute to improved haemostasis. Despite improved haemostasis, bleeding during pregnancy is a common symptom reported in women with bleeding disorders.

In individual bleeding disorders, out of 7 idiopathic thrombocytopenic purpuric patients 4 had obstetrical problems which included 4 primary PPH in the present pregnancy and 1 had PPH in the past pregnancy. Out of 5 patients of vWD only 2 presented with the obstetrical problems which included $1 \mathrm{PPH}$ and 1 infertility. With the exception of HIV induced thrombocytopenia all the other bleeding disorder patients had obstetric problems.

In this study post-partum haemorrhage was a major obstetrical problem accounting for $59 \%$ of the total obstetrical problems. Primary PPH was more common than secondary PPH and also PPH was associated with other obstetric problems like past history of $\mathrm{PPH}$ or recurrent pregnancy loss. Patients of ITP, factor XI deficiency and SLE with ITP with APLA had higher incidence of PPH per pregnancies as compared to other disorders. All the patients were managed conservatively with oxytocin and prostaglandin analogue and blood and blood products.

An increased risk of miscarriage and placental abruption resulting in fetal loss or premature delivery among women with deficiency of FXIII or fibrinogen has been reported. ${ }^{11}$ Recurrent pregnancy loss was another obstetric problem found in $33 \%$ in our study. 9 of the 30 patients had history of RPL. The incidence of RPL was more common in patients of Protein $\mathrm{C}$ and $\mathrm{S}$ deficiency, APLA syndrome, SLE with ITP with APLA, factor XI deficiency and vWD with protein $\mathrm{C}$ and $\mathrm{S}$ deficiency. Low molecular weight heparin has become a routine treatment for women with RPL with acquired and heritable thrombophilias. A recent systemic review in which the data on use of anticoagulants, showed that there was $30 \%$ reduction in pregnancy loss with its use. ${ }^{12}$ Also it has been shown that heparin and aspirin results in significant better pregnancy outcomes than low dose aspirin alone in women with APA and RPL. ${ }^{13}$

In this present study all pregnant patients RPL patients were managed with heparin and aspirin, of which only 2 could complete the term and had full term normal vaginal delivery, 3 patients had preterm vaginal delivery and 1 patient had incomplete abortion.

\section{CONCLUSION}

On analysing the combined obstetric and gynaecological problems the present study found that gynaecological problems were more prevalent $(70 \%)$ compared to obstetric problems $(66.66 \%)$. There is a growing body of evidence that the quality of life of women with inherited bleeding significantly diminished by both obstetric and gynaecological problem.
Management needs to be individualized and is best undertaken jointly and in a coordinated fashion by the family physician, the haematologist, and the gynaecologist. Pregnancy is not contraindicated in patients with coagulation disorders but requires a multidisciplinary approach to management. Ideally, there should be a pre-pregnancy discussion between the future parents and the medical team. Optimal management of these problems requires a multidisciplinary team approach which includes a haematologist and Obstetrician.

Funding: No funding sources Conflict of interest: None declared

Ethical approval: The study was approved by the Institutional Ethics Committee

\section{REFERENCES}

1. Roberts HR, Escobar MA. Other clotting factor deficiencies. In: Hoffman R, Benz EJ Jr, Shattil SJ, Cohen HJ, Silberstein LE, McGlave P, eds. Hematology: Basic Principles and Practice. 4th edn. NYC: Churchill Livingstone; 2005.

2. Barr RD, Sek J, Horsman J, Furlong W, Saleh M, Pai $M$, et al. Health status and health-related quality of life associated with von Willebrand's Disease. Am J Hematol. 2003;73:108-14.

3. Kouides PA, Burkart P, Phatak PD, Porter J, Peacock L, Braggins C, et al. The substantial impact of von Willebrand's disease on menstruation. Update Obstet Gynecol. 1998;5:153-4.

4. Kadir RA, Sabin CA, Pollard D, Lee CA, Economides DL. Quality of life during menstruation in patients with inherited bleeding disorders. Haemophila 1998;4:836-41.

5. Shankar M, Chi C, Kadir RA. Review of quality of life: menorrhagia in women with or without inherited bleeding disorders. Haemophilia. 2008;14(1):15-20.

6. Barr RD, Sek J, Horsman J, Furlong W, Saleh M, Pai $\mathrm{M}$, et al. Health status and health-related quality of life associated with von Willebrand's disease. Am J Hematol. 2003;73(2):108.

7. ACOG. Management of anovulatory bleeding. American College of Obstetricians and Gynaecologists: Washington DC: 2000:1-12.

8. Siboni SM, Calo L, Santagostino E, Mancuso ME, Gianniello F, Federici AB, et al. Gynaecological and Obstetrical problems in women affected with inherited bleeding disorders $\mathbf{J}$ Thromb Haemost. 2007;5(2): O-W-021.

9. Payne JH, Maclean RM, Hampton KK, Baxter AJ, Makris M. Haemoperitoneum associated with ovulation in women with bleeding disorders: the case for conservative management and the role of the contraceptive pill. Haemophilia. 2007;13(1):93-7.

10. Bremme KA. Haemostatic changes in pregnancy. Best Pract Res Clin Haematol. 2003;16(2):153-68.

11. Lee CA, Chi C, Pavord SR, Bolton-Maggs PH, Pollard D, Hinchcliffe-Wood A, et al. The obstetric 
and gynaecological management of women with inherited bleeding disorders- review with guidelines produced by a taskforce of UK Haemophilia Centre Doctors' Organization.

Haemophilia. 2006;12(4):301-36

12. Empson M, Lessere M, Creig J, Scott J. Recurrent pregnancy loss with antiphospholipid antibody or lupus anticoagulant. Chochrane Database Syst Rev. 2005;2:CD002859.
13. Rai R, Cohen H, Dave M, Regan L. Randomized controlled trial of aspirin and aspirin plus heparin in pregnant women with recurrent miscarriages associated with phospholipid antibodies (or antiphospholipid antibodies). BMJ. 1997;314:253-7.

Cite this article as: Panchbudhe SA, Desai AS. Assessment of obstetric and gynaecological problems in females with bleeding disorders. Int J Reprod Contracept Obstet Gynecol 2021;10:1573-9. 